\title{
Preparation of hydrophobic PVDF hollow fiber membranes for desalination through membrane distillation
}

\author{
Deyin Hou, Jun Wang, Dan Qu, Zhaokun Luan, Changwei Zhao \\ and Xiaojing Ren
}

\begin{abstract}
Fabrication of polyvinylidene fluoride (PVDF) hydrophobic asymmetric hollow fiber membranes was studied by introducing inorganic salt LiCl and water soluble polymer polyethylene glycol (PEG) 1500, using $\mathrm{N}, \mathrm{N}$-dimethylacetamide (DMAC) as solvent and tap water as the coagulation medium. The membranes properties also were tested and characterized. It is found that the nonsolvent additive can increase membranes porosity, ether LiCl or PEG 1500. Because of the addition of PEG 1500, the PVDF membranes obtained a rough topography on the membrane surface and the contact angle of the PVDF membranes increased to $113.50^{\circ}$ compared to $89.82^{\circ}$ of the PVDF membranes spun without an additive. During direct contact membrane distillation (DCMD) of 0.6 M sodium chloride solution, the PVDF membranes spun with PEG 1500 as a non-solvent additive achieved higher water permeation flux compared to the membranes spun from PVDF/DMAC and PVDF/DMAC/LiCl dopes, but the latter two membranes exhibited higher salt rejection rate.
\end{abstract}

Key words | desalination, hollow fiber, hydrophobic, membrane distillation, PVDF

\section{INTRODUCTION}

Membrane distillation (MD) is a new membrane separation process usually applied in where water is the major component present in the feed solution to be treated. The permeate flux of MD is driven by a vapor pressure difference across the membrane resulting from the temperature difference and solution composition gradients in the boundary layers adjacent to the membrane (Feng et al. 2004). The MD process may be used as a substitute for conventional separation processes such as multistage vacuum evaporation, RO, and distillation (Lawson \& Lloyd 1997).Compared to those processes, the advantages of MD (Hanemaaijer et al. 2006) are as follows: (1) lower operating temperature and vapor space required than conventional distillation, (2) lower operating pressure than RO, (3) 100\% (theoretical) rejection of non-volatile doi: $10.2166 /$ wst.2009.080

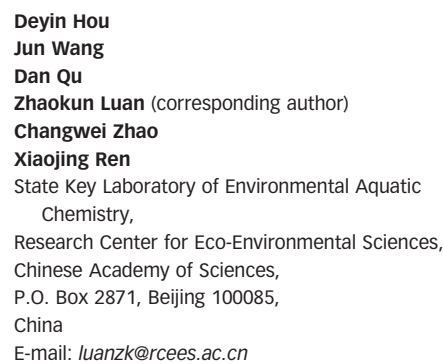

E-mail: luanzk@rcees.ac.cn

solute, (4) unlimited by high osmotic pressure, and (5) lower energy consumption than multistage vacuum evaporation.

MD processes have several configurations which can be configured as direct contact membrane distillation (DCMD), air gap membrane distillation (AGMD), sweeping gas membrane distillation (SGMD) and vacuum membrane distillation (VMD). More details and extended explanations of the MD process can be found in several articles (Khayet et al. 2000; Urtiaga. et al. 2000; Amali. et al. 2004; Cath et al. 2004; Guijt et al. 2005; EL-Bourawi et al. 2006). In these existing modes, most MD experiments are carried out by using DCMD, which is convenient to set up, consumes relatively low energy, gives high water permeate flux and appears to be the best for application (Phattaranawik \& Jiraratananon 200I). 
For an MD process, the porous membrane only acts as a barrier, but it plays a crucial role. The membrane prevents the penetration of the aqueous solution into its dry pores by its hydrophobic nature until the liquid entry pressure of water (i.e., LEPw) is exceeded. Besides, the membrane properties, such as pore size, pore size distribution and porosity will also influence the MD performance (Tomaszewska I996; Gryta 2007). Therefore, excellent hydrophobicity, appropriate pore size and narrow pore size distribution of microporous membranes are necessary to ensure the high permeate flux and rejection coefficient in the MD process.

Nowadays, polytetrafluoroethylene (PTFE), polypropylene (PP) and polyvinylidene fluoride (PVDF) are the most popular and available hydrophobic membrane materials. Among these three polymers, only PVDF can be used for the preparation of asymmetric membranes using the LoebSourirajan phase inversion method. It is also one of the polymers that is thermally stable, possesses good chemical resistance, and is resistant to most of corrosive chemicals. Hence, PVDF has been the subject of active research in polymer science and has received increasing attention for various membrane separations (Khayet et al. 2002). Although an extensive series of studies has been carried out to fabricate various PVDF membranes in order to improve membrane properties, most of them are focused on preparation of flat sheet membranes (Lin et al. 2002; Fontananova et al. 2006; Buonomenna et al. 2007; Seol et al. 2007) and hydrophilic composite hollow fiber membranes (Singh et al. 2005; Feng et al. 2006; Wu et al. 2006; Zhao et al. 2008; Zhou \& Xi 2008). On the contrary, as far as we know, less research has been conducted on the fabrication and characterization of hydrophobic porous PVDF hollow fiber membranes mainly for the MD process.

The present investigation aims to investigate the science and engineering of membrane formation and spinning conditions for the fabrication of porous hydrophobic PVDF hollow fiber membranes, and test and characterize the membranes via DCMD.

\section{MATERIALS AND METHODS}

PVDF (FR-904) was obtained from Shanghai 3F new materials Co., Ltd. (China). The molecular weight (Mw) of
PVDF is about $1.02 \times 10^{6} \mathrm{~g} \mathrm{~mol}^{-1}$, measured by GPC (waters, 515). N, N-dimethylacetamide (DMAc, >99\%) was employed as the solvent, purchased from Shanghai Jingwei Chemical Co., Ltd. (China). Polyethylene glycol (PEG) $1500(\mathrm{Mw}=1500,>99.5 \%)$ and $\mathrm{LiCl}(95.0 \%)$ were supplied by Tianjin Guangfu Research Institute of Fine Chemical Engineering (China). Ethanol (GR grade, 99.9\%) and $\mathrm{NaCl}(99.5 \%)$ were from Beijing Chemical works (China). Ultrapure water and tap water were used as the bore liquid and external coagulant, respectively.

\section{Dope preparation}

The PVDF powder was dried at $100^{\circ} \mathrm{C}$ under vacuum for $24 \mathrm{~h}$ to remove its moisture content before it was used for dope preparation. A desired amount of dried PVDF powder was weighed and poured into a DMAc solvent and nonsolvent additive mixture, then the polymer dope mixture was subjected to continuous stirring for about $48 \mathrm{~h}$ at $50^{\circ} \mathrm{C}$ in order to ensure that it was homogeneous.

Although a dope solution with a low polymer concentration tends to result in microporous membranes (Reuvers \& Smolders I987; Radovanovic et al. I992; Bonyadi \& Chung 2007), it is necessary to adopt an appropriate additive as a pore former to improve the permeation performance of the membranes via adjusting the membrane structure. Therefore, in this work, the polymer solutions of PVDF/DMAc/LiCl (12/83/5 wt\%) and PVDF/DMAc/PEG $1500(12 / 83 / 5 \mathrm{wt} \%)$ were chosen to fabricate hydrophobic porous PVDF membranes. Another PVDF/DMAc $(12 / 88 \mathrm{wt} \%)$ dope solution was prepared for comparison.

\section{Spinning of PVDF hollow fiber membranes}

The method of preparation involved is the same as that of the 'phase inversion' method employed in earlier works as reported by other researchers (Wang et al. 2004; Chung et al. 2000), and the process of hollow fiber spinning is schematically shown in Figure 1. The formulated dope and bore fluid were filtered by a metal filter $(15 \mu \mathrm{m})$ and degassed before spinning to remove the particles and gas bubbles that may exist in the dope. The homogenous polymer solution was fed into the spinneret by a gear pump with a speed controller under the nitrogen pressure of $0.2 \mathrm{MPa}$, and ultrapure water 


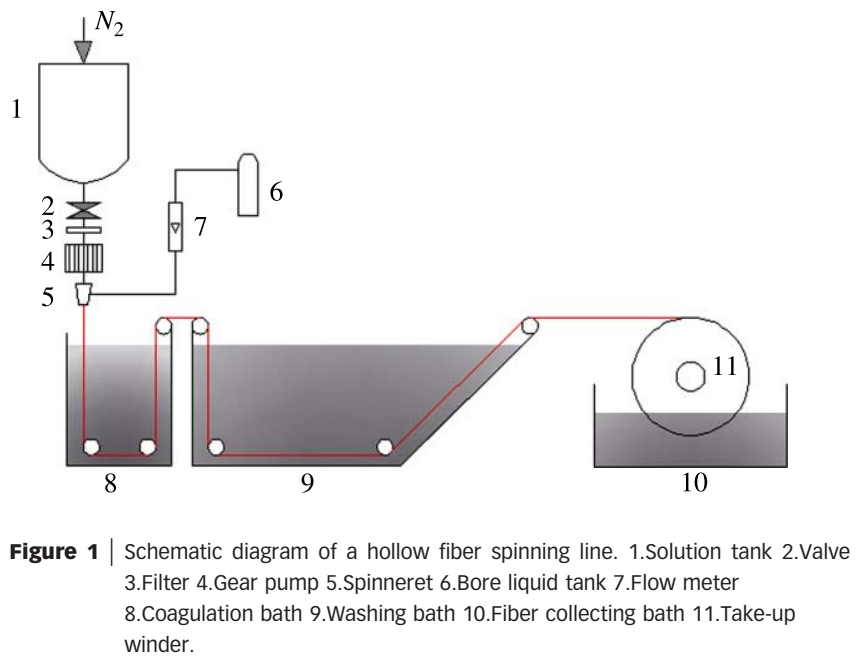

was used as bore liquid fed into the spinneret through a flow meter under the same nitrogen pressure to make a lumen of the hollow fiber. The spinneret had outer and inner tubers, the diameters of that were 1.4 and $0.7 \mathrm{~mm}$, respectively. Once the spinning dope and the bore liquid met at the tip of the spinneret, they entered the coagulation bath straight away. The nascent fiber was wound on a take-up winder after entering into a water bath kept at $20^{\circ} \mathrm{C}$ to induce the phase separation and solidify the membrane. The as-spun fibers were soaked in ethanol bath for 3 days to remove the residual solvent and non-solvent additives from the resultant membranes. At last, the wetting fibers were dried in air at room temperature until ready to receive hydrophobic porous membranes. The spinning conditions and detailed parameters are listed in Table 1.

\section{Membrane characterization}

The morphology of the membrane was investigated with a HITACHI S-3000N scanning electron microscope (SEM) (Hitachi Ltd., Japan). Membrane samples were frozen in liquid nitrogen, fractured to obtain fragments, and sputtered with platinum using a HITACHI E-1010 Ion Sputtering device for SEM observation.

The hydrophobicity of the hollow fiber was exhibited by gauges of contact angle of droplets with the OCA20 Video-Based Contact Angle Meter (DataPhysics Instruments Ltd., Germany). Water droplets of about $0.5 \mu \mathrm{l}$ were carefully dropped onto the as-prepared coating
Table 1 | Process parameters and spinning conditions

\begin{tabular}{ll} 
Process parameters/spinning conditions & Value \\
\hline Dope solution composition $\left(\mathrm{wt}^{\circ} / 0\right)$ & $\begin{array}{l}\text { PVDF/DMAc/LiCl } \\
(12 / 83 / 5) \mathrm{PVDF} / \mathrm{DMAc} /\end{array}$ \\
& PEG 1500 $(12 / 83 / 5)$ \\
& PVDF/DMAc $(12 / 88)$ \\
& 20 \\
Dope extrusion rate $\left(\mathrm{ml} \mathrm{min}^{-1}\right)$ & $1.4 / 0.7$ \\
Spinneret OD/ID ${ }^{*}\left(\mathrm{~mm} \mathrm{~mm}^{-1}\right)$ & ultrapure water \\
Bore liquid & $10-20$ \\
Bore liquid flow rate $\left(\mathrm{ml} \mathrm{min}^{-1}\right)$ & tap water \\
External coagulant & $8-10$ \\
Air-gap distance $(\mathrm{cm})$ & 20 \\
Coagulant temperature $\left({ }^{\circ} \mathrm{C}\right)$ & $60-75$ \\
Room relative humidity $(\%)$ &
\end{tabular}

*Outer Diameter/Inner Diameter.

through a syringe under ambient temperature and the contact angles were obtained by measuring five different positions of each sample.

Asymmetric microporous membranes were characterized by the determination of porosity and mean radius. The overall porosity can usually be determined by gravimetric method, determining the weight of liquid contained in the membrane pores. The porosity $\varepsilon$ of the PVDF hollow fiber was calculated by the following equations:

$\varepsilon=\frac{\left(w_{1}-w_{2}\right) / D_{W}}{\left(w_{1}-w_{2}\right) / D_{W}+w_{2} / D_{P}}$,

where $w_{1}$ is the weight of the wet membrane, $w_{2}$ is the weight of the dry membrane, $D_{\mathrm{W}}$ is the water density and $D_{\mathrm{P}}$ is the polymer density.

Mean pore size was investigated by filtration velocity method, measuring the ultrafiltration flux of the wet membrane in limited time under 0.1 MPa pressure. Mean pore size $R_{f}$ was calculated according to the following revised form of the Guerout-Elford-Ferry equation (1):

$R_{f}=\sqrt{\frac{(2.90-1.75 \varepsilon) 8 \eta h Q}{\varepsilon P A}}$

where $\eta$ is the water viscosity, $h$ the membrane thickness, $Q$ is the flux per unit time, $P$ is the operation pressure $(0.1 \mathrm{MPa})$ and $A$ is the effective membrane area.

Experiments of DCMD with $0.6 \mathrm{~mol}^{-1}$ aqueous sodium chloride solution were carried out to evaluate the 


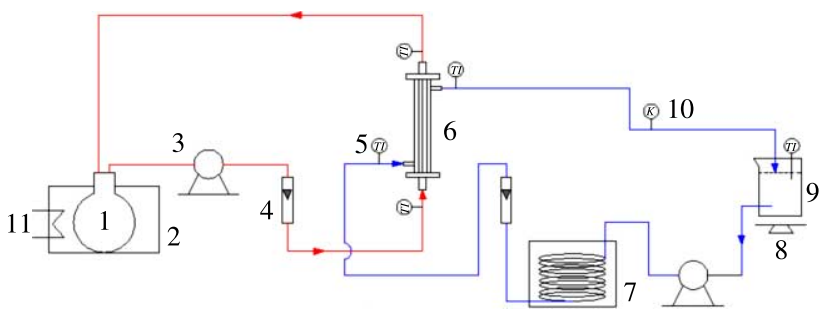

Figure 2 Schematic diagram of the experimental DCMD set-up. 1. Feed reservoir 2. Water bath 3. Pump 4. Flow meter 5. Thermometer 6. Membrane module 7. Cooling coil 8. Balance 9. Permeate reservoir 10. Conductivity meter 11. Heater.

permeate performance of prepared membranes. The schematic representation of DCMD set-up is shown in Figure 2. The dry PVDF hollow fibers $150 \mathrm{~mm}$ in length were assembled into a polyester tube (diameter ( $\mathrm{mm}$ ) $d_{\text {in }} / d_{\text {out }}=15 / 20$ ) with two UPVC T-tubes and two ends of the bundle of fibers were sealed with solidified epoxy resin to form a membrane module. The effective membrane length was about $100 \mathrm{~mm}$. The hot aqueous sodium chloride solution as the feed liquid flowed through the lumen side of the fibers, whereas the cold ultrapure water flowed through the shell side. Both solutions were circulated in the membrane module with the help of two magnetic pumps (MP-15RN, Shanghai Seisun Bumps, China). The circulation feed rate was $601 \mathrm{~h}^{-1}$, while the permeate side was $65 \mathrm{~L} / \mathrm{h}$, which were adjusted by two rotameters (LZS-15, Yuyao Yinhuan Flowmeter, China). The feed liquid and the cold ultrapure water flowed cocurrently through the module and their temperatures were controlled by water baths. The temperature of both fluids was monitored at the inlet and outlet of the membrane module using four Pt-100 thermoresistances connected to a digital meter (Digit RTD, model XMT-808, Yuyao Changjiang Temperature Meter Instruments, China) with an accuracy of $\pm 0.1^{\circ} \mathrm{C}$.
The concentration of $\mathrm{NaCl}$ in the distillate cold water was investigated with an electric conductivity monitor (CM-230A, Shijiazhuang Create Instrumentation Technologies, China). The permeation flux of the membranes $J$ was calculated by the following equation:

$J=\frac{\Delta W}{A \Delta t}$,

where $J$ is the permeation flux $\left(\mathrm{kg} \mathrm{m}^{-2} \mathrm{~h}^{-1}\right), \Delta W$ is the quantity of distillate $(\mathrm{kg}), A$ is the inner surface area of the hollow fiber membranes $\left(\mathrm{m}^{2}\right)$ and $\Delta t$ is the sampling time (h).

The rejection coefficient $R$ of hollow fiber membranes was calculated according to the following equation:

$R=\frac{C_{f}-C_{p}}{C_{f}}$

where $C_{f}$ is the concentration of the feed and $C_{p}$ is the concentration of the permeate.

\section{RESULTS AND DISCUSSIONS}

\section{Effect of non-solvent additives on membranes morphology}

Figures 3-5 shows the morphology of the hollow fibers prepared from different dope solutions. Larger and longer macrovoids from the inner wall can be observed in the fibers spun with 5 wt.\% PEG 1500 additives (Figure 4, M-2a) in comparison with that without an additive (Figure 3, M-1a). While as $\mathrm{LiCl}$ added into the system, the size of macrovoids decreased, the structure being stretched down like a finger from the underneath of membrane skin (Figure 3, M-3a). The presence of PEG 1500 favored the formation of thinner fiber skins, which was confirmed from the cross-section

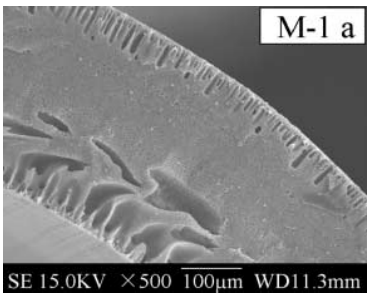

Cross section

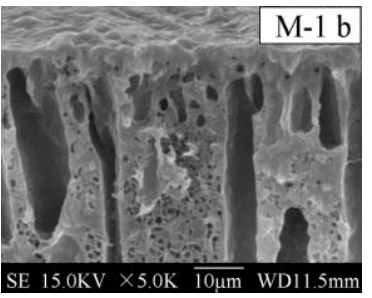

Cross section near outer layer

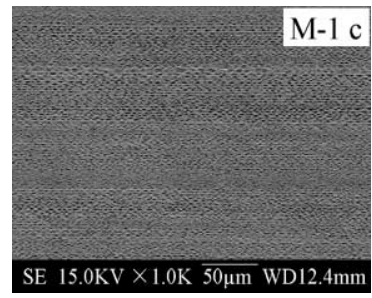

Inner surface

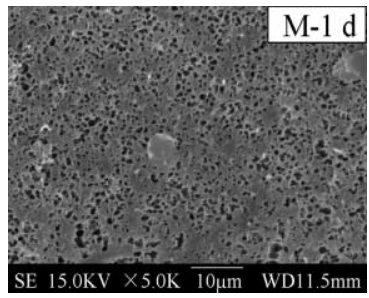

Middle structure

Figure 3 | SEM morphology of PVDF hollow fiber membrane from the PVDF/DMAC dope solution. 


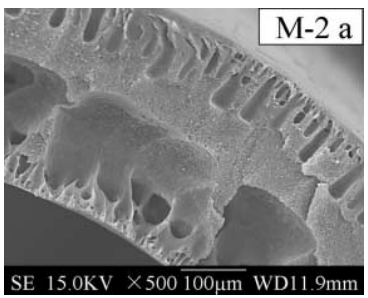

Cross section

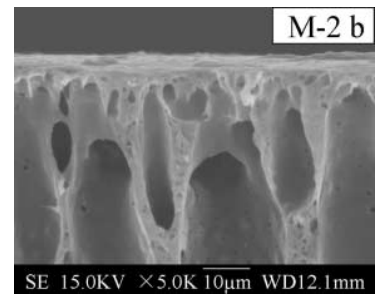

Cross section near outer layer

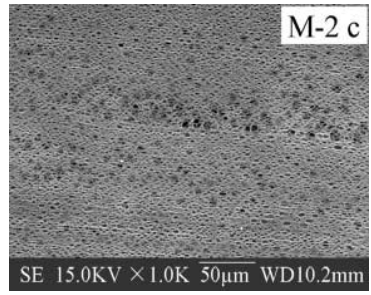

Inner surface

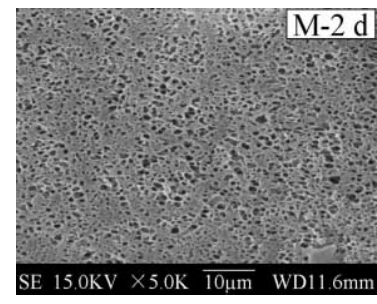

Middle structure

Figure 4 | SEM morphology of PVDF hollow fiber membrane from the PVDF/DMAC/PEG 1500 dope solution.

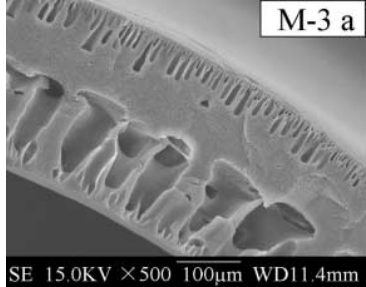

Cross section

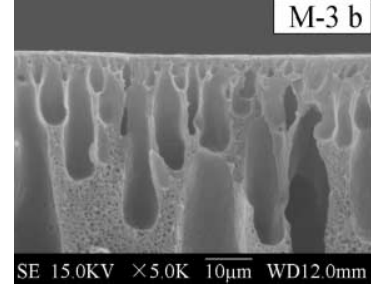

Cross section near outer layer

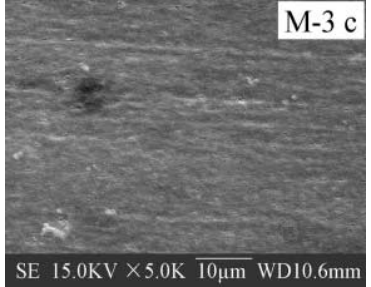

Inner surface

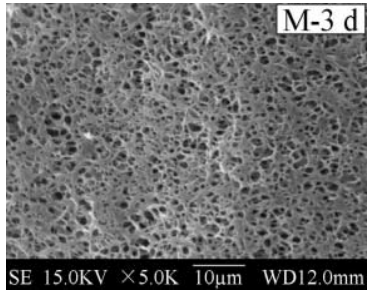

Middle structure

Figure 5 | SEM morphology of PVDF hollow fiber membrane from the PVDF/DMAC/LiCl dope solution.

morphology near the outer layer (Figure 3, M-2b) when compared with the membranes prepared with PEG 1500 as the additive and without it (Figure 3, M-1b and Figure 5, M-3b). Between the cavities beneath the outer and inner skin of the hollow fibers, the cross-section morphology of all the membranes was altered to the sponge-like structure. With the addition of $\mathrm{LiCl}$ in the dope, it was found that the micropores in the middle structure increased apparently (Figure 5, M-3d), but the pore size of the membranes surface became obviously smaller (Figure 5, M-3c).

The above observations can be associated with the variation of the thermodynamic and kinetic properties of the dope system with different non-solvent additives. Compared with the system without an additive, PEG 1500 addition increased the dope's thermodynamic instability in reaction with water due to its non-solvent effect, which facilitated a rapid phase demixing and resulted in macrovoids and ultra-thin skin formation, thus the PEG 1500 acted as a phase separation enhancer. $\mathrm{LiCl}$ possessed strong interactions with the polymer and solvent; the addition of it can enhance the viscosity of the PVDF/DMAc dope solution significantly. The strong interactions between the components of the dope tended to delay the dope precipitation, so the macrovoids became smaller and developed to the finger-like structures; at the same time, the sponge-like structures changed to be more porous and the porosity of the membranes improved.

\section{Characterization of hollow fiber membranes}

It was reported that the hydrophobicity of membranes can be greatly enhanced by creating a rough topography on the membrane surface (Hong et al. 2008). Because of the addition of PEG 1500, the contact angle of the PVDF membranes increased to $113.50^{\circ}$ compared to $89.82^{\circ}$ of the dense PVDF membranes. The porosity of the M-3 hollow fibers was 77.5\%, whereas the porosity of the M-1 and M-2 membranes were $68.7 \%, 72.4 \%$, respectively. This further verified that both of the non-solvent additives can enhance membrane porosity.

Typical membranes applied in membrane distillation generally possess microfiltration properties with a pore size of $0.1-1 \mu \mathrm{m}$ and provide a membrane thickness of 10-300 $\mu \mathrm{m}$ (Albrecht et al. 2005). The mean pore diameter of the M-2 membrane was $0.96 \mu \mathrm{m}$, which was the largest in the three fibers. Compared to the $\mathrm{M}-1$ and $\mathrm{M}-2$ membranes, the mean pore size of the M-3 became much smaller. All of the four fibers owned the same membrane thickness of $0.13 \mathrm{~mm}$, which was in the range of $10-300 \mu \mathrm{m}$. The more detailed data on membrane characteristics is listed in Table 2 . 
Table 2 | Measured data of membranes characteristics

\begin{tabular}{lcllcc} 
Membrane code & Contact angle $\left({ }^{\circ}\right)$ & Porosity (\%) & Mean pore diameter $(\boldsymbol{\mu m})$ & OD $(\mathbf{m m})$ & WDall thickness $(\mathbf{m m})$ \\
\hline M-1 & 89.82 & 68.7 & 0.83 & 0.13 & 0.98 \\
M-2 & 113.50 & 72.4 & 0.96 & 0.13 \\
M-3 & 91.86 & 77.5 & 0.16 & 0.94 & 1.20 \\
\hline
\end{tabular}

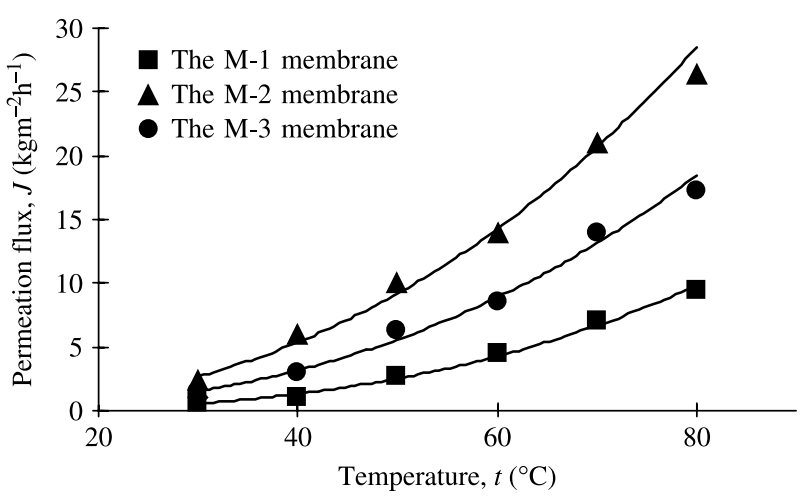

Figure 6 | Permeation flux as a function of feed temperature (salt solution flow rate $60 \mathrm{I}^{-1} \mathrm{~min}$, cold distillate water $18.0^{\circ} \mathrm{C}$, flow rate $65 \mathrm{I} \mathrm{min}^{-1}$ ).

\section{Membranes permeation performance in membrane distillation process}

The fabricated fibers were tested for the DCMD process. During the experiment, the hot $0.6 \mathrm{moll}^{-1}$ aqueous sodium chloride solution and the cold water, co-currently flow through the lumen and shell sides of the hollow fibers, respectively. The inlet temperature of the hot salt solution, $T_{f}$, is adjusted from 30 to $80^{\circ} \mathrm{C}$ and the inlet temperature of the cold distillate, $T_{p}$, is kept at a constant $18.0^{\circ} \mathrm{C}$. The water permeation flux based on the fiber's inner surface area is shown in Figure 4. It can be observed that the PVDF/
DMAc/PEG 1500 dope produces membranes with much higher flux compared with other two hollow fibers. During the desalination press, although the temperature difference at the outlet of the membrane module is $43.7^{\circ} \mathrm{C}$ as compared to $63.8^{\circ} \mathrm{C}$ at the inlet of the membrane module, the transmembrane water permeation flux can achieve $26.4 \mathrm{kgm}^{-2} \mathrm{~h}^{-1}$ when the inlet temperature of the hot solution is $81.8^{\circ} \mathrm{C}$. It must be noted that although the M-2 membrane achieved the greatest permeation flux, the $\mathrm{NaCl}$ rejection rate of it was the lowest. On the contrary, the $\mathrm{NaCl}$ rejection rate of the M-1 and M-3 membranes achieved 100\% (Figure 6).

\section{Comparison with other MD membranes}

Table 3 lists a performance comparison between the current work and the previous investigations. It can be observed that the obtained data in this study is comparable to most of the previous reports. It is believed that if the membrane fabrication optimizations which were attempted in this work are accompanied with more efficient module designs to improve the flow pattern and suppress the temperature polarization phenomenon, even higher flux is achievable in the MD process. In the future, we are going to optimize the

Table 3 | Comparison of the maximum flux obtained in this study with the literature for DCMD processes

\begin{tabular}{|c|c|c|c|c|c|c|}
\hline Membrane & Reference & $\begin{array}{l}\text { Maximum flux } \\
\left(\mathrm{kg} \mathrm{m}^{-2} \mathrm{~h}^{-1}\right)\end{array}$ & Feed & $\begin{array}{l}\text { Feed inlet } \\
\text { temperature } \\
\left({ }^{\circ} \mathrm{C}\right)\end{array}$ & $\begin{array}{l}\text { Permeate inlet } \\
\text { temperature } \\
\text { ('C) }\end{array}$ & Configuration \\
\hline F2.4 flat sheet membrane & [Feng. et al. (2004) & 7.3 & $0.3 \mathrm{~mol} \mathrm{l}^{-1} \mathrm{NaCl}$ & 55 & 25 & Concurrent \\
\hline PTFE flat sheet membrane & [Phattaranawik et al. (2003) & 32.4 & $1 \mathrm{wt} \% \mathrm{NaCl}$ & 90 & 17 & Cross-flow \\
\hline PVDF flat sheet membrane & Peng et al. (2005) & 23.7 & $3.5 \mathrm{wt} \% \mathrm{NaCl}$ & 70 & 12 & Cross-flow \\
\hline PP hollow fiber & Gryta \& Tomaszewska (I998) & 28 & $1 \mathrm{wt} \% \mathrm{NaCl}$ & 80 & 20 & Concurrent \\
\hline PP hollow fiber & Gryta et al. (200I) & 13.5 & $3.5 \mathrm{wt} \% \mathrm{NaCl}$ & 85 & 20 & Concurrent \\
\hline PVDF hollow fiber & This study & 26.4 & $0.6 \mathrm{~mol} \mathrm{l}^{-1} \mathrm{NaCl}$ & 81.8 & 18.0 & Concurrent \\
\hline
\end{tabular}


membrane structure, enhance the hydrophobicity and porosity of the membrane and improve the rejection rate of salt.

\section{CONCLUSIONS}

In the present work, the inorganic salt $\mathrm{LiCl}$ and water soluble polymer polyethylene glycol (PEG) 1500 were introduced to fabricate polyvinylidene fluoride (PVDF) hydrophobic asymmetric hollow fiber membranes, using $N, N$-dimethylacetamide (DMAc) as solvent and tap water as the coagulation medium. It is found that the non-solvent additive can increase membrane porosity, ether $\mathrm{LiCl}$ or PEG 1500. Because of the addition of PEG 1500, the PVDF membranes obtained a rough topography on the membrane surface and the contact angle of the PVDF membranes increased to $113.50^{\circ}$ compared to $89.82^{\circ}$ of the PVDF membranes spun without additive.

These as-spun membranes were applied in the DCMD process. During the desalination process of $0.6 \mathrm{~mol}^{-1}$ sodium chloride solution, the membrane spun from PVDF/DMAc/PEG 1500 dope solution achieved the highest permeation flux of $26.4 \mathrm{~kg} \mathrm{~m}^{-2} \mathrm{~h}^{-1}$ and a $\mathrm{NaCl}$ rejection of $95.8 \%$ with a hot salt solution at $81.8^{\circ} \mathrm{C}$ and cold distillation water at $18.0^{\circ} \mathrm{C}$.

Areas for further study include: (1) further optimization of membrane characteristics such as thickness, pore size and its distribution, surface and bulk porosities and membrane contact angle, (2) exploring new module designs to improve the flow pattern and suppress the temperature polarization phenomenon, and (3) investigation of the heat and mass transfer mechanisms and simulation of the effects of temperature and concentration polarization on the heat, mass transfer during MD process, and (4) long time running membrane performance test.

\section{$\overline{\text { ACKNOWLEDGEMENTS }}$}

Financial support provided by the National Natural Science Foundation of China (Grant no. 50678169) and Research Foundation of The Chinese Academy of Sciences for Youth Scholars (the project of preparation and optimization of hydrophobic hollow fibers and membrane modules) are gratefully acknowledged.

\section{REFERENCES}

Albrecht, W., et al. 2005 Selection of microporous hydrophobic membranes for use in gas/liquid contactors: an experimental approach. J. Memb. Sci. 263, 66-76.

Amali, A. E., et al. 2004 Experimental study of air gap and direct contact membrane distillation configurations: application to geothermal and seawater desalination. Desalination 168, 357.

Bonyadi, S. \& Chung, T. S. 2007 Flux enhancement in membrane distillation by fabrication of dual layer hydrophilichydrophobic hollow fiber membranes. J. Memb. Sci. 306, 134-146.

Buonomenna, M. G., et al. 2007 Poly(vinylidene fluoride) membranes by phase inversion: the role the casting and coagulation conditions play in their morphology, crystalline structure and properties. Eur. Polym. J. 43, 1557-1572.

Cath, T. Y., et al. 2004 Experimental study of desalination using direct contact membrane distillation: a new approach to flux enhancement. J. Memb. Sci. 228, 5-16.

Chung, T. S., et al. 2000 Effect of membrane structure on masstransfer in the membrane gas-liquid contacting process using microporous PVDF hollow fibers. Chem. Eng. Sci. 55, $1077-1091$.

El-Bourawi, M. S., et al. 2006 A framework for better understanding membrane distillation separation process. J. Memb. Sci. 285, 4-29.

Feng, C. S., et al. 2004 Preparation and properties of microporous membrane from poly(vinylidene fluoride-cotetrafluoroethylene) (F2.4) for membrane distillation. J. Memb. Sci. 237, 15-24.

Feng, C. S., et al. 2006 Factors affecting pore structure and performance of poly(vinylidene fluoride-co-hexafluoro propylene) asymmetric porous membrane. J. Memb. Sci. 277, $55-64$.

Fontananova, E., et al. 2006 Effect of additives in the casting solution on the formation of PVDF membranes. Desalination 192, 190-197.

Gryta, M. \& Tomaszewska, M. 1998 Heat transport in the membrane distillation process. J. Memb. Sci. 144, 211-222.

Gryta, M., et al. 200I Membrane distillation of $\mathrm{NaCl}$ solution containing natural organic matter. J. Memb. Sci. 181, 279-287.

Gryta, M. 2007 Influence of polypropylene membrane surface porosity on the performance of membrane distillation process. J. Memb. Sci. 287, 67-68.

Guijt, C. M., et al. 2005 Air gap membrane distillation 2. Model validation and hollow fibre module performance analysis. Sep. Purif. Technol. 43, 245-255.

Hanemaaijer, J. H., et al. 2006 Memstill membrane distillation-a future desalination technology. Desalination 199, 175-176.

Hong, Y. C., et al. 2008 A facile method for the fabrication of super-hydrophobic surfaces and their resulting wettability. Scr. Mater. 59, 776-779.

Khayet, M., et al. 2000 Theory and experiments on sweeping gas membrane distillation. J. Memb. Sci. 165, 261-272. 
Khayet, M., et al. 2002 Preparation and characterization of polyvinylidene fluoride hollow fiber membranes for ultrafiltration. Polymer 43, 3879-3890.

Lawson, K. W. \& Lloyd, D. R. 1997 Membrane distillation. J. Memb. Sci. 124, 1-25.

Lin, D. J., et al. 2002 Microporous PVDF membrane formation by immersion precipitation from water/TEP/PVDF system. Desalination 145, 25-29.

Peng, P., et al. 2005 Desalination by membrane distillation adopting a hydrophilic membrane. Desalination 137, 45-54.

Phattaranawik, J. \& Jiraratananon, R. 200I Direct contact membrane distillation: effect of mass transfer on heat transfer. J. Memb. Sci. 188, 137-143.

Phattaranawik, J., et al. 2003 Effect of pore size distribution and air flux on mass transport in direct contact membrane distillation. J. Memb. Sci. 215, 75-85.

Reuvers, A. J. \& Smolders, C. A. 1987 Formation of membranes by means of immersion precipitation. Part II. J. Memb. Sci. 34, 67-86.

Radovanovic, P., et al. 1992 Formation of asymmetric polysulfone mem branes by immersion precipitation. part II. J. Memb. Sci. 65, 231-246.

Seol, W. H., et al. 2007 Enhancement of the mechanical properties of PVDF membranes by non-solvent aided morphology control. Journal of Power Sources 170, 191-195.
Singh, N., et al. 2005 Surface modification of microporous PVDF membranes by ATRP. J. Memb. Sci. 262, 81-90.

Tomaszewska, M. 1996 Preparation and properties of flat-sheet membranes from poly(vinylidene fluoride) for membrane distillation. Desalination 104, 1-11.

Urtiaga, A. M., et al. 2000 Kinetic analysis of the vacuum membrane distillation of chloroform from aqueous solutions. J. Memb. Sci. 165, 99-110.

Wang, K. Y., et al. 2004 The effects of flow angle and shear rate within the spinneret on the separation performance of poly(ethersulfone) (PES) ultrafiltration hollow fiber membranes. J. Memb. Sci. 240, 67-79.

$\mathrm{Wu}, \mathrm{L}$. S., et al. 2006 Poly(vinylidene fluoride)/polyethersulfone blend membranes: effects of solvent sort, polyethersulfone and polyvinylpyrrolidone concentration on their properties and morphology. J. Memb. Sci. 285, 290-298.

Zhao, Y. H., et al. 2008 Modification of porous poly(vinylidene fluoride) membrane using amphiphilic polymers with different structures in phase inversion process. J. Memb. Sci. 310, $567-576$.

Zhou, Y. \& Xi, D. L. 2008 Porous PVDF/TPU blends asymmetric hollow fiber membranes prepared with the use of hydrophilic additive PVP (K30). Desalination 223, $438-447$. 